\title{
Dual Gamma Rhythm Generators Control Interlaminar Synchrony in Auditory Cortex
}

\author{
Matthew Ainsworth, ${ }^{1}$ Shane Lee, ${ }^{2}$ Mark 0. Cunningham, ${ }^{1}$ Anita K. Roopun, ${ }^{1}$ Roger D. Traub,${ }^{4}$ Nancy J. Kopell, ${ }^{2,3}$ \\ and Miles A. Whittington ${ }^{1}$ \\ ${ }^{1}$ Institute of Neuroscience, Newcastle University, Newcastle, NE2 4HH, United Kingdom, ${ }^{2}$ Graduate Program in Neuroscience and ${ }^{3}$ Department of \\ Mathematics and Statistics, Boston University, Massachusetts 02215, and ${ }^{4}$ Department of Physical Sciences, IBM T. J. Watson Research Center, New York, \\ New York 10598
}

Rhythmic activity in populations of cortical neurons accompanies, and may underlie, many aspects of primary sensory processing and short-term memory. Activity in the gamma band $(30 \mathrm{~Hz}$ up to $>100 \mathrm{~Hz})$ is associated with such cognitive tasks and is thought to provide a substrate for temporal coupling of spatially separate regions of the brain. However, such coupling requires close matching of frequencies in co-active areas, and because the nominal gamma band is so spectrally broad, it may not constitute a single underlying process. Here we show that, for inhibition-based gamma rhythms in vitro in rat neocortical slices, mechanistically distinct local circuit generators exist in different laminae of rat primary auditory cortex. A persistent, $30-45 \mathrm{~Hz}$, gap-junction-dependent gamma rhythm dominates rhythmic activity in supragranular layers $2 / 3$, whereas a tonic depolarization-dependent, $50-80 \mathrm{~Hz}$, pyramidal/interneuron gamma rhythm is expressed in granular layer 4 with strong glutamatergic excitation. As a consequence, altering the degree of excitation of the auditory cortex causes bifurcation in the gamma frequency spectrum and can effectively switch temporal control of layer 5 from supragranular to granular layers. Computational modeling predicts the pattern of interlaminar connections may help to stabilize this bifurcation. The data suggest that different strategies are used by primary auditory cortex to represent weak and strong inputs, with principal cell firing rate becoming increasingly important as excitation strength increases.

\section{Introduction}

Rhythmic activity in the EEG gamma band is a near-ubiquitous feature of ongoing cortical activity and responses to sensory input. Activity within the gamma band is involved in multiple aspects of cortical computation, most stemming from the close relationship between the rhythm, particularly the faster gamma components, and spike generation in cortical neurons (Rasch et al., 2008; Ray et al.,2008), and its ability to temporally control and segregate spikes in multiple spatially separate neurons (Engel and Singer, 2001; Fries, 2005). There is good evidence that the resulting patterns of synchrony and coherence in cortex form the basis of a code for many aspects of sensory representation and shortterm memory (Engel et al., 2001; Kaiser and Lutzenberger, 2005).

In vitro work has revealed a variety of mechanisms underlying gamma rhythms (Whittington et al., 2011), each operating around a common principal: the presence of phasic

Received May 3, 2011; revised Sept. 6, 2011; accepted Sept. 25, 2011.

Author contributions: M.A.W. designed research; M.A., S.L., and A.K.R. performed research; M.O.C., R.D.T., N.J.K., and M.A.W. analyzed data; M.A.W. wrote the paper.

This work was supported by the Wolfson Foundation and the Engineering and Physical Sciences Research Council (EPSRC). M.A. is a doctoral student funded as part of the EPSRC CARMEN (Code Analysis, Repository, and Modelling for e-Neuroscience) e-science project. S.L. is a doctoral student and was supported by National Science Foundation (NSF) Grant DMS-0602204. R.D.T. was supported by IBM, NIH/NINDS Grants NS44133 and NS062955, and Alexander von Humboldt Stiftung. N.J.K. was supported by NSF Grants DMS-0717670 and DMS-0602204 and NIH/NINDS Grant NS062955.

Correspondence should be addressed to M. A. Whittington, Institute of Neuroscience, Medical School, Newcastle University, Framlington Place, Newcastle upon Tyne, NE2 4HH, UK. E-mail: m.a.whittington@ncl.ac.uk.

DOI:10.1523/JNEUROSCI.2209-11.2011

Copyright $\odot 2011$ the authors $\quad 0270-6474 / 11 / 3117040-12 \$ 15.00 / 0$
$\mathrm{GABA}_{\mathrm{A}}$ receptor-mediated synaptic inhibition. This mechanism breaks down at frequencies $\sim 90 \mathrm{~Hz}$ and higher (Traub et al., 1996b), but nominally the gamma rhythm encompasses a very broad range of frequencies from $\sim 30 \mathrm{~Hz}$ up to as high as $200 \mathrm{~Hz}$ (Crone et al., 2006; Jerbi et al., 2009); this is too broad to consider the gamma rhythm a single mechanistic entity (Siegel and König, 2003) and, more importantly, too broad to implicate activity in the entire band as a unifying mode of intercortical communication (Uhlhaas et al., 2011). The question remains, however, as to whether these factors need also to be considered for different frequencies within the narrower range associated with phasic inhibition $(30-90 \mathrm{~Hz})$.

In single cortical areas, in which the lower, $\sim 40 \mathrm{~Hz}$, gamma is manifest, it is also common to find higher frequencies (Crone et al., 1998; Edwards et al., 2005; Pipa et al., 2009; Le Van Quyen et al., 2010). These observations suggest the possibility of a single, very broadly tuned oscillator. However, even for inhibitionbased gamma rhythms $(<90 \mathrm{~Hz})$, in vitro studies show different local codependent mechanisms (Gloveli et al., 2005; Middleton et al., 2008) and anatomical separation of sources across different laminae (Oke et al., 2010). Combined computational and experimental approaches show that lower-frequency gamma rhythms originate from layers $2 / 3$, and higher frequencies originate particularly from layer 4 (Lachaux et al., 2005). These latter frequencies can be seen to be selectively enhanced in epilepsy (Traub et al., 2001, 2005).

In an attempt to further address the issues of local circuit origin and mechanism(s) of inhibition-based $(30-90 \mathrm{~Hz})$ 
gamma rhythms, here we vary excitation levels in primary auditory cortex (A1) in in vitro slice and computational models. Both these approaches show the continued presence of a low (30-45 $\mathrm{Hz}$ ) gamma rhythm, generated in layer $2 / 3$. Increasing excitatory drive to this cortical region causes frequency bifurcation: the reestablishment of a low-frequency $(30-45 \mathrm{~Hz})$ rhythm concurrently with a more variable, higher-frequency rhythm (50-80 $\mathrm{Hz}$ ) originating in layer 4 . The two rhythms arise from fundamentally different local circuit mechanisms.

\section{Materials and Methods}

Experimental. Horizontal neocortical slices, $450 \mu \mathrm{m}$ thick, containing A1 were prepared from 86 adult male Wistar rats $(150-250 \mathrm{~g})$. Slices were maintained at $34^{\circ} \mathrm{C}$ at the interface between warm wetted $95 \% \mathrm{O}_{2} / 5 \% \mathrm{CO}_{2}$ and artificial CSF (aCSF) containing the following (in $\mathrm{mm}$ ): $3 \mathrm{KCl}, 1.25$ $\mathrm{NaH}_{2} \mathrm{PO}_{4}, 1 \mathrm{MgSO}_{4}, 1.2 \mathrm{CaCl}_{2}, 24 \mathrm{NaHCO}_{3}, 10$ glucose, and $126 \mathrm{NaCl}$. Gamma rhythms were generated by bath application of 200-800 nu kainate to mimic the active, "up state" of cortex in rodents (Cunningham et al., 2006). Pharmacological manipulation was performed by bath application of drugs: gabazine (1 $\mu \mathrm{M})$, SYM2206 [( \pm )-4-(4-aminophenyl)-1,2-dihydro-1methyl-2-propylcarbamoyl-6,7-methylenedioxyphthalazine] $(20 \mu \mathrm{M})$, PPDA [1-(phenanthrine-2-carbonyl) piperazine-2,3-dicarboxylate] (10 $\mu \mathrm{M})$, and carbenxolone ( $0.2 \mathrm{~mm})$.

Extracellular recordings from A1 were obtained using glass micropipettes containing the above aCSF (resistance, $<0.5 \mathrm{M} \Omega$ ). Intracellular recordings were taken with sharp microelectrodes filled with potassium acetate (resistance, 30-90 M $\Omega$ ). Signals were digitized at $10 \mathrm{kHz}$. Multichannel unit and concurrent local field potential time-series data were recorded at $30 \mathrm{kHz}$ using $10 \times 10$ array $(0.4 \mathrm{~mm}$ separation $)$ Utah silicon probes or $1 \times 10$ electrode array $(0.1 \mathrm{~mm}$ separation; FHC), amplified, digitized with a Cyberkinetics amplifier, and analyzed offline using Central (Blackrock Systems). Local field potentials were downsampled to 1 $\mathrm{kHz}$ and bandpass filtered $(1-100 \mathrm{~Hz})$. Current source density was estimated using ICSD to compensate for edge effects (Pettersen et al., 2006), and laminar power and frequency distribution were calculated from this. All ICSD data were taken from linear electrode arrays placed radially (pial to white matter) across the middle of the slice. Column diameter was assumed to be slice thickness (see above). No edge compensation was required for deep layer recordings because the linear array extended beyond the white matter. However, parameters were modified to compensate for the transition from neuropil at the pial surface to the pure aCSF volume conductor around the slice perimeter. Laminar borders were determined by distance from pial surface under bright-field illumination at $40 \times$ magnification.

Spike probability values were calculated by taking 1000 consecutive field potential periods and quantifying the number of concurrently observed spikes for each cell type within this time. Dividing the number of spikes observed by the number of periods elapsed gave a probability value for each slice tested. Estimates of EPSP and IPSP amplitudes were taken by injecting current into the recorded cells to hold mean membrane potential at $-30 \mathrm{mV}$ (for IPSP analysis) or $-70 \mathrm{mV}$ (for EPSP analysis). Event parameters were analyzed using Minianalysis (Synaptosoft).

Model. The computational model of Al considered anatomical evidence outlining interlaminar connections (Thomson and Bannister, 2003; Atencio and Schreiner, 2010) and our experimental observations of mechanistically distinct local circuit generators in this study. The model consisted of three layers: supragranular layer $2 / 3$, granular layer 4 , and the supragranular layer 5 (see Fig. 6Ci). Each layer comprised 25 regular spiking excitatory $(E)$ cells and five fast spiking inhibitory $(I)$ cells that were mutually coupled within a layer. The number of cells used in the model reflects a qualitative estimate of the ratio of excitatory/inhibitory cells. The number of excitatory cells was chosen to provide the model with enough heterogeneity while maintaining computational efficiency; far less heterogeneity was required in the inhibitory cells in this model. Cells in layer $2 / 3$ are denoted with a subscript "s," cells in layer 4 are denoted with a subscript " $g$," and cells in layer 5 are denoted with a subscript " $i$," which should not be confused for "inhibitory." Because this model is concerned primarily with the generation of gamma frequency rhythms, which are thought to involve primarily soma and proximal dendrites (Gillies et al., 2002) (see Fig. 3) of pyramidal cells, single compartmental Hodgkin-Huxley models were used for simplification and provide good correlation with simulations from more detailed biophysical models (Kopell et al., 2000).

From layer 4 to layer $2 / 3$, there was a feedforward excitatory connection from $E_{g}-E_{s}$ and a feedforward inhibitory connection from $I_{g}-I_{s}$. From layer $2 / 3$ to layer 4 , there was a feedback excitatory connection from $E_{s}-I_{g}$ and a feedback inhibitory connection from $I_{s}-E_{g}$. From layer $2 / 3$ to layer 5 , there were feedforward excitatory connections from $E_{s}-E_{i}$ and $E_{s}-I_{i}$. From layer 4 to layer 5 , there were feedforward excitatory connections from $E_{g}-E_{i}$ and $E_{g}-I_{i}$. In this simplified model, there were no feedback connections from layer 5 to more superficial layers.

In layer $2 / 3$, the $E_{s}$ cells received a baseline tonic excitatory applied current and stochastic excitatory inputs that resulted in a persistent (weak) gamma rhythm in which only a small, random population of $E_{s}$ cells fired on each cycle, whereas most of the $I_{s}$ cells fired on each cycle. The $E_{s}$ cells in layer $2 / 3$ also included a model for a slow potassium M-like current as a result of experimental suggestions that M-type potassium currents in superficial layers may be important in sound sequence discrimination in A1 (Kudoh et al., 2004). In this layer, kainate-induced excitation was modeled by increasing the Poisson rate of the stochastic excitatory inputs to the $E_{s}$ cells, which is consistent with the observation that increases in kainate concentration maintain the sparse firing rate and network frequency. In the physiological system, and in detailed biophysical models of layer $2 / 3$ gamma rhythms, gap junctionally connected axons have been shown to be essential. However, the central function of the resulting axo-axonal plexus, in the production of gamma rhythms at least, can be simplified down to a provision of noisy drive to the participating cells. In this reduced model, the "noise" is still essential and is provided directly by stochastic (Poisson-distributed) inputs to the excitatory cell populations rather than explicit modeling of gap junctions.

In layer 4 , the $E_{g}$ cells were connected to a population of $I_{g}$ cells that resulted in a pyramidal cell-interneuron gamma (PING) rhythm that was driven by a baseline excitatory input to the $E_{g}$ cells. The $E_{g}$ cells had synaptic connections from other $E_{g}$ cells, modeling NR2C/D-dependent NMDAR-mediated currents. Kainate-induced excitation in this layer was modeled by increasing the amplitude of the tonic current to the $E_{g}$ cells, which increases the frequency of the layer 4 rhythm in which the excitatory cells spike on each cycle of the rhythm, as experimentally observed.

The units for voltages are expressed in millivolts. Current units are expressed in microamperes per square centimeters. Conductance units are expressed in millisiemens per square centimeters. Opening rates are expressed in millimolar per millisecond, and closing rates are per millisecond. All time constants are expressed in milliseconds. The specific membrane capacitance $\left(C_{m}\right)$ was $1 \mu \mathrm{F} / \mathrm{cm}^{2}$. The intralaminar parameters, as well as the interlaminar synaptic variable parameters, were derived from Börgers et al. (2005). The values for the intralaminar parameters were chosen to exhibit qualitative behavior consistent with experimental observations for each layer. Namely, the layer 2/3 network parameters were chosen to enable sparse spiking in the excitatory cell population that would create a background gamma frequency rhythm. In layer 4 , the experimental data suggested that the excitatory cells need to be spiking on each cycle of the local field oscillation. A qualitative minimization technique was used to ensure that the values of the parameters were chosen to be plausibly physiological while still maintaining the necessary behavior in the network. Because of the nonlinearity of the network, a very large parameter space may exist that exhibits the physiological constraints. However, once fixed, the interlaminar connection values were used to gauge the effect of these connections on the different laminar network models. Care was taken the ensure that the order of magnitude of these values did not become implausible, but the values of the conductances in this model may not be physiologically meaningful, considering the spatial reductions that have been used in the tradeoff between computational efficiency and biological relevance. Indeed, depending on the magnitude of the values chosen in each network, similar qualitative behavior may result from different interlaminar parameter 
values. Because this model focuses on how these connections might play a role in influencing a network phenomenon of the frequencies of the network oscillations, it is the qualitative and relative strengths of the connections that may be more critical to understanding the network phenomenon and not the actual values used.

Each of the excitatory $(e)$ and inhibitory $(i)$ cell voltages $(v)$ were described by the following:

$C_{m} \frac{d v_{(e, i)}}{d t}=-I_{L(e, i)}-I_{\mathrm{Na}(e, i)}-I_{\mathrm{K}(e, i)}-I_{\mathrm{K}_{\mathrm{M}}(e)}-I_{s(e, i)}-I_{(e) \mathrm{psp}}+I_{\mathrm{app}(e, i)}$,

for leak, sodium $\left(\mathrm{Na}^{+}\right)$, potassium $\left(\mathrm{K}^{+}\right)$, M-like potassium (only $E_{s}$ cells), synaptic $(s)$, stochastic EPSP, only $E_{s}, E_{g}$, and $E_{i}$ cells), and applied currents (app), respectively.

Unless otherwise noted, the activation variables (represented generally here by $m$ ) followed the general form

$$
\begin{gathered}
\dot{m}=\frac{m_{\infty}-m}{\tau_{m}}, \\
m_{\infty}=\frac{\alpha_{m}}{\alpha_{m}+\beta_{m}} .
\end{gathered}
$$

$\mathrm{Na}^{+}$currents. Because the activation of the $\mathrm{Na}^{+}$currents were relatively fast compared with the kinetics of the other dynamical variables, the steady-state activation variable $\left(m_{\infty}\right)$ was used to reduce the dimensionality of the system of differential equations. The $\mathrm{Na}^{+}$currents were given in general by

$$
\begin{gathered}
I_{\mathrm{Na}}=\hat{g}_{\mathrm{Na}} \cdot m_{\infty}^{3} h \cdot\left(v-E_{\mathrm{Na}}\right), \\
m_{\infty}=\frac{\alpha_{m}}{\alpha_{m}+\beta_{m}} .
\end{gathered}
$$

For the $E_{g}, E_{s}$, and $E_{i}$ cells, $\hat{g}_{\mathrm{Na}}=100$ and $E_{\mathrm{Na}}=50$. For the $I_{g}, I_{s}$, and $I_{i}$ cells, $\hat{g}_{\mathrm{Na}}=35$ and $E_{\mathrm{Na}}=40$.

For the excitatory $E_{i}$ cells of layer $5, E_{g}$ cells of layer 4 , and $E_{s}$ cells of layer $2 / 3, m_{\infty}$ were given by

$$
\begin{gathered}
\alpha_{m}=\frac{0.33 \cdot\left(v_{e}+50\right)}{1-\exp \left(-\frac{v_{e}+50}{4}\right)}, \\
\beta_{m}=\frac{0.25 \cdot\left(v_{e}+25\right)}{\exp \left(\frac{v_{e}+25}{5}\right)-1} .
\end{gathered}
$$

The inactivation variables $h$ were given by

$$
\begin{gathered}
\alpha_{h}=0.128 \cdot \exp \left(-\frac{v_{e}+50}{18}\right), \\
\beta_{h}=4 \cdot\left[1-\exp \left(-\frac{v_{e}+27}{5}\right)\right]^{-1} .
\end{gathered}
$$

For the inhibitory $I_{i}, I_{g}$, and $I_{s}$ cells, rate equations for $m_{\infty}$ were given by

$$
\begin{gathered}
\alpha_{m}=\frac{0.1 \cdot\left(v_{i}+35\right)}{1-\exp \left(-\frac{v_{i}+35}{10}\right)}, \\
\beta_{m}=4 \cdot \exp \left(-\frac{v_{i}+60}{18}\right) .
\end{gathered}
$$

Rate equations for the inactivation variables $h$ were given by

$$
\begin{gathered}
\alpha_{h}=0.07 \cdot \exp \left(-\frac{v_{i}+58}{20}\right), \\
\beta_{h}=\left[\exp \left(-0.1 \cdot\left(v_{i}+28\right)\right)+1\right]^{-1} .
\end{gathered}
$$

Other intrinsic currents. The leak currents were given by

$$
I_{L}=0.1 \cdot\left(v-E_{L}\right)
$$

with $E_{L}=-70$. The leak currents were identical across different cell types for simplicity, since the nonlinear dynamics of our synaptic and other intrinsic currents may compensate for these differences.

The $\mathrm{K}^{+}$currents for all cells were given by

$$
I_{\mathrm{K}}=\hat{g}_{\mathrm{K}} \cdot n^{4} \cdot\left(v-E_{\mathrm{K}}\right) \text {. }
$$

For all cells, $\hat{g}_{\mathrm{K}}=80$. For $E_{i}, E_{g}$, and $E_{s}$ cells, $E_{\mathrm{K}}=-1$, and for $I_{i}, I_{g}$, and $I_{s}$ cells, $E_{\mathrm{K}}=-90$.

For the activation variable $n$, the rate functions for excitatory $E_{i}, E_{g}$, and $E_{s}$ cells were given by

$$
\begin{aligned}
\alpha_{n} & =\frac{0.032 \cdot\left(v_{e}+52\right)}{1-\exp \left(-\frac{v_{e}+52}{5}\right)}, \\
\beta_{n} & =0.5 \cdot \exp \left(-\frac{v_{e}+57}{40}\right) .
\end{aligned}
$$

The rate functions for the inhibitory $I_{i}, I_{g}$, and $I_{s}$ cells were given by

$$
\begin{aligned}
\alpha_{n} & =\frac{0.01 \cdot\left(v_{i}+34\right)}{\exp \left(-0.1 \cdot\left(v_{i}+34\right)\right)-1}, \\
\beta_{n} & =0.125 \cdot \exp \left(-\frac{v_{i}+44}{80}\right) .
\end{aligned}
$$

In the model, only the $E_{s}$ cells in layer $2 / 3$ included a non-inactivating M-like current, which followed previous modeling work (Mainen and Sejnowski, 1996; McCarthy et al., 2008) and was given by

$$
I_{\mathrm{K}_{\mathrm{M}}}=\hat{g}_{\mathrm{K}_{\mathrm{M}}} \cdot m_{\mathrm{M}} \cdot\left(v-E_{\mathrm{K}}\right) \text {. }
$$

The conductance $\hat{g}_{K_{M}}=0.35$. The rate functions were given by

$$
\begin{aligned}
\alpha_{m_{\mathrm{M}}} & =\frac{2.3 \cdot 10^{-4} \cdot\left(v_{e}+30\right)}{1-\exp \left(-\frac{v_{e}+30}{9}\right)}, \\
\beta_{m_{\mathrm{M}}} & =\frac{2.3 \cdot 10^{-4} \cdot\left(v_{e}+30\right)}{1-\exp \left(\frac{v_{e}+30}{9}\right)} .
\end{aligned}
$$

Synaptic currents. The model adapted synaptic parameter values and equations from a model of persistent (weak) PING (Börgers et al., 2005). Synaptic currents $\left(I_{s}\right)$ were defined between connected pairs of model cells from cell of type $j$ to an excitatory cell of type $k$ by

$$
I_{s j, k(e)}=\phi_{j, k(e)} \cdot \sum_{i}\left(g_{j, k(e)} \cdot s_{j, k(e)}\right)\left(v_{k(e)}-E_{j}\right) .
$$

Synaptic currents were defined from cell of type $j$ to an inhibitory cell of type $k$ by

$$
I_{s j, k(i)}=0.5 \cdot \phi_{j, k(i)} \cdot \sum_{j}\left(g_{j, k(i)} \cdot s_{j, k(i)}\right)\left(v_{k(i)}-E_{j}\right) .
$$

For excitatory cells, the reversal potential $E_{j(e)}=0$. For inhibitory cells, $E_{j(i)}=-80$. The synaptic connection matrix $(\Phi)$ was created such that each presynaptic cell $j$ made connections to a fraction $(\rho)$ of postsynaptic cells. The values for $\rho$ are found in Table 1 . Conductance values $\left(g_{j, k}\right)$ were scaled by the mean number of connections made by each presynaptic cell: this provides heterogeneity to a postsynaptic cell while maintaining a relatively scale-independent order of magnitude of the strength of the connection. Synaptic conductances are defined in Table 2. The relevant interlaminar connections were qualitatively guided by anatomical and physiological studies noting the strength and density of connections (Thomson and Bannister, 2003; Atencio and Schreiner, 2010) and 
Table 1. Values of connection fraction parameters $\boldsymbol{\rho}_{j, k}$

\begin{tabular}{lllllll}
\hline & $E_{g(j)}$ & $I_{g(k)}$ & $E_{s(k)}$ & $I_{s(k)}$ & $E_{i(k)}$ & $I_{i(k)}$ \\
\hline$E_{g(j)}$ & 1 & 1 & 0.20 & 0 & 1 & 1 \\
$I_{g(j)}$ & 1 & 0 & 0.20 & 1 & 0 & 0 \\
$E_{s(j)}$ & 0 & 0 & 0 & 1 & 1 & 0.2 \\
$I_{s(j)}$ & 0.20 & 0 & 1 & 0 & 0 & 0 \\
$E_{(j)}$ & 0 & 0 & 0 & 0 & 0 & 1 \\
$I_{i(j)}$ & 0 & 0 & 0 & 0 & 1 & 0 \\
\hline
\end{tabular}

Table 2. Values of synaptic conductance parameters $\boldsymbol{g}_{j, k}$

\begin{tabular}{lllllll}
\hline & $E_{g(k)}$ & $I_{g(k)}$ & $E_{s(k)}$ & $I_{s(k)}$ & $E_{i(k)}$ & $I_{i(k)}$ \\
\hline$E_{g(j)}$ & 0.055 & 0.39 & 0.01 & 0 & 0.07 & 0.2 \\
$I_{g(j)}$ & 0.60 & 0 & 0 & 0.7 & 0 & 0 \\
$E_{s(j)}$ & 0 & 0 & 0 & 5.0 & 0.1 & 1.7 \\
$I_{s(j)}$ & 0.25 & 0 & 1.0 & 0 & 0 & 0 \\
$E_{i(j)}$ & 0 & 0 & 0 & 0 & 0 & 1 \\
$I_{i(j)}$ & 0 & 0 & 0 & 0 & 0.1 & 0 \\
\hline
\end{tabular}

then tuned to fit the qualitatively observed field and intracellular experimental data reported here.

For all synaptic connections, the dynamics of the synaptic variable $s_{j}, k$ were defined from cell $j$ to cell $k$ by

$$
\dot{s}_{j, k}=\frac{1+\tanh \left(\frac{v_{j}}{10}\right)}{2 \tau_{r(j)}} \cdot\left(1-s_{j, k}\right)-\frac{s_{j, k}}{\tau_{d(j)}}
$$

where $\tau_{r}$ was the rise time constant, and $\tau_{d}$ was the decay time constant. For excitatory presynaptic cells, $\tau_{r}=0.1$ and $\tau_{d}=3.0$. For inhibitory presynaptic cells, $\tau_{r}=0.3$ and $\tau_{d}=9.0$. The $E_{g}-E_{g}$ connections to model the NR2C/D-dependent NMDAR-mediated currents were defined within this framework with $\tau_{d}=20$, without a voltage-dependent $\mathrm{Mg}^{2+}$ sensitivity (Binshtok et al., 2006).

Current contributions from stochastic inputs to the excitatory cells were inspired by previous work (Börgers et al., 2005) and were given by

$$
\begin{gathered}
I_{e \mathrm{psp}}=\hat{g}_{e \mathrm{psp}} \cdot s_{\text {epsp }} \cdot\left(v-E_{e}\right), \\
\dot{s}_{\text {epsp }}=\delta \cdot\left(1-s_{\text {epsp }}\right)-\frac{s_{\text {epsp }}}{\tau_{e \mathrm{psp}}},
\end{gathered}
$$

with the conductance $\hat{g}_{\text {epsp }}=1$ for $E_{s}, E_{g}$, and $E_{i}$ cells. The reversal potential $E_{e}=0$, and the decay time constant $\tau_{\text {epsp }}=3$. The values for $\delta$ were chosen in each time step of the integration $d t$ as a binomial distribution approximation of a Poisson process with rates $f_{(s, g, i), \text { epsp. }}$.

Kainate-induced excitation. The effects of kainate were modeled differently in layer $2 / 3$ and layer 4 . In layer $2 / 3$, kainate-induced excitation was modeled by increasing $f_{s, \text { epsp }}$ to the $E_{s}$ cells. These cells received a baseline $I_{\text {app }, e s}$ of $1.35 \mu \mathrm{A} / \mathrm{cm}^{2}$. In layer 4, kainate-induced excitation was modeled by increasing the amplitude of the tonic excitation $I_{\text {app }, e g}$ to the $E_{g}$ cells. These cells also received stochastic excitatory inputs with $f_{g \text {,epsp }}$ of $65 \mathrm{~Hz}$. In the model, layer 5 does not respond to kainate directly but responds to feedforward excitation from the more superficial layers. Layer 5 received a baseline $\mathrm{I}_{\text {app }, e i}$ of $0.5 \mu \mathrm{A} / \mathrm{cm}^{2}$ and stochastic excitatory inputs with $f_{i, \text { epsp }}$ of $40 \mathrm{~Hz}$.

Analysis. The contribution of synaptic currents to the excitatory cells were calculated and averaged in each layer as the model estimation of a local field potential. Standard discrete Fourier transforms were used to analyze the spectral content of the mean synaptic activity. In our single compartmental idealization, the magnitude of the local field potentials are artificial measures of the strengths of oscillations that does not reflect physiological measures accurately; for this reason, field potentials are amplitude normalized within a layer. Each simulation was run for $500 \mathrm{~ms}$ of simulation time. The system of equations was numerically integrated by a fourth-order Runge-Kutta method using a fixed time step of 0.025 $\mathrm{ms}$, similar to work done by others for this class of models (Compte et al., 2003, Rubin and Terman, 2004). Some papers with Poisson-distributed stochastic events similar to ours have used a second-order Runge-Kutta integration scheme modified for noise (Tiesinga et al., 2000), but it has been suggested that, for numerical simulations in which the stochastic part is completely determined by sequences of pseudorandom numbers, the order of error is most dependent on the error of the deterministic part (Saito and Matsui, 1993). To test stability for the deterministic part, the time step in our model was reduced to $0.015 \mathrm{~ms}$, which produced numerically identical results. Increasing the time step to $0.035 \mathrm{~ms}$ did as well. However, the instability for our system was apparent at 0.05 and 0.1 ms. The choice of $0.025 \mathrm{~ms}$ reflected a compromise between stability, accuracy, and computational efficiency. Each simulation was run for 500 ms of simulation time. The system of differential equations was numerically integrated by a fourth-order Runge-Kutta method using a fixed time step of $0.025 \mathrm{~ms}$, which represented deviations from the previous work from which this model was partially derived (Börgers et al., 2005), in hopes of improving numerical accuracy. All simulations and analyses were performed in MATLAB version 7.10.0.499 (MathWorks).

\section{Results}

\section{Increasing cortical excitation causes frequency bifurcation in the gamma band}

Increasing bath concentrations of kainate from 200 to $600 \mathrm{nM}$ caused a small, significant increase in local field potential gamma frequency in A1. Modal peaks in power spectra began to appear after $30 \mathrm{~min}$ incubation with $200 \mathrm{~nm}$ kainate, but power was weak $\left(2.2 \pm 0.5 \times 10^{-10} \mathrm{~V}^{2}, n=5\right)$ and peak frequency highly variable, including the beta band $(27 \pm 8 \mathrm{~Hz}, n=5)$. At $400 \mathrm{~nm}$, a clear spectral peak was visible (power, $8.5 \pm 0.6 \times 10^{-10} \mathrm{~V}^{2}, n=$ 5 ), with a mean frequency of $37 \pm 3 \mathrm{~Hz}$, not significantly faster than the lower concentration $(p>0.05, n=5)$. An additional increase in frequency was seen with $600 \mathrm{~nm}$ kainate $(45 \pm 7 \mathrm{~Hz})$, significantly faster than that seen at $200 \mathrm{~nm}(p<0.05, n=5$; Fig. $1 \mathrm{Ai}$ ) but with no overt change in power compared with $400 \mathrm{~nm}$ kainate. Higher concentrations of kainate generated dual gamma peaks robustly; the lower of these had frequency and power not significantly different from $400 \mathrm{~nm}$ kainate $(p>$ $0.05, n=5)$. However, the additional faster gamma peak occurred at $55 \pm 2 \mathrm{~Hz}$, with clear separation on individual and pooled spectra (Fig. 1 Aii).

To determine the origin of the faster gamma frequency after spectral bifurcation, a laminar profile of both peak power and frequency of the local field potential was constructed under 800 nm kainate for the lower $(30-45 \mathrm{~Hz})$ and higher $(50-80 \mathrm{~Hz})$ gamma bands (Fig. $1 B$ ). Peak power in the lower-frequency band was seen in layer 3 , whereas peak power in the higher-frequency band was seen in layers $4 / 5$ (Fig. $1 B$ ). More detailed estimates of laminar sources for the rhythms, derived from current source density, showed a clearer laminar separation of underlying currents. Before bifurcation, peak gamma frequency current amplitude was seen in layer $2 / 3$, with a weaker signal in lower layer 4/upper layer 5 (Fig. 1C). The layer 2/3, lower-frequency gamma rhythm was relatively unchanged after bifurcation (with $800 \mathrm{nM}$ kainate), but a stronger, more spectrally distributed signal was now evident at higher frequencies in layer 4.

\section{The two gamma rhythms have different underlying mechanisms}

Gamma rhythms up to $\sim 90 \mathrm{~Hz}$ in local circuits can arise from many mechanisms, each involving phasic $\mathrm{GABA}_{\mathrm{A}}$ receptormediated inhibition and most also requiring phasic AMPA receptor-mediated drive to interneurons (Whittington et al., 2011). Both gamma rhythms, seen after bifurcation here, were highly sensitive to blockade of $\mathrm{GABA}_{\mathrm{A}}$ receptors with gabazine ( 1 $\mu \mathrm{M})$, with reduction in field power down to $\sim 10 \%$ of control 


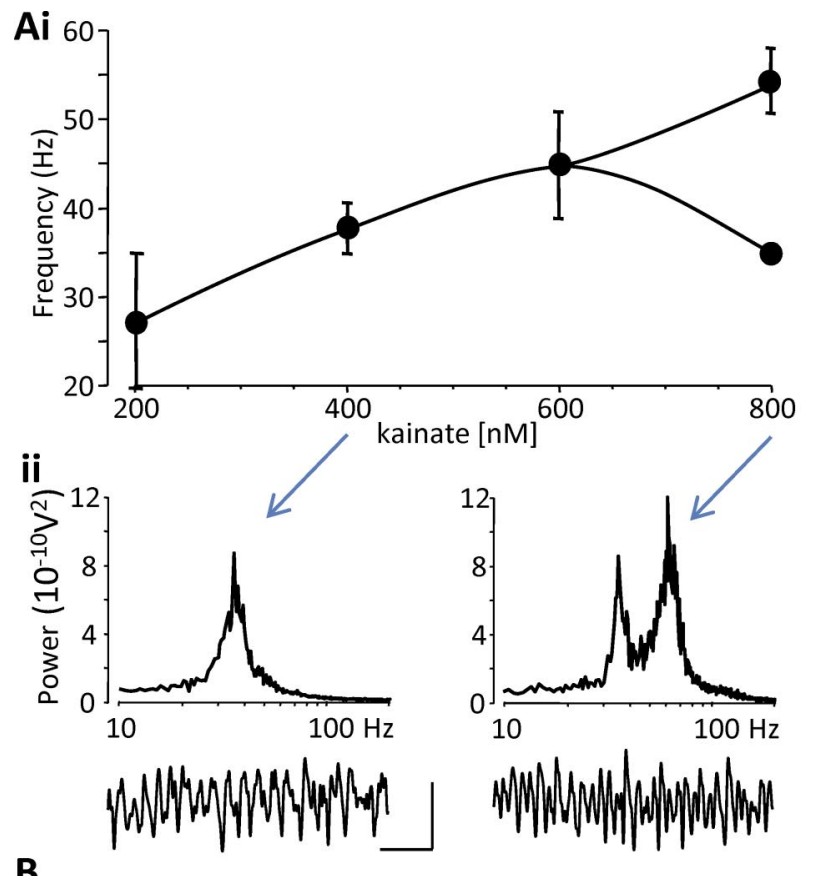

B

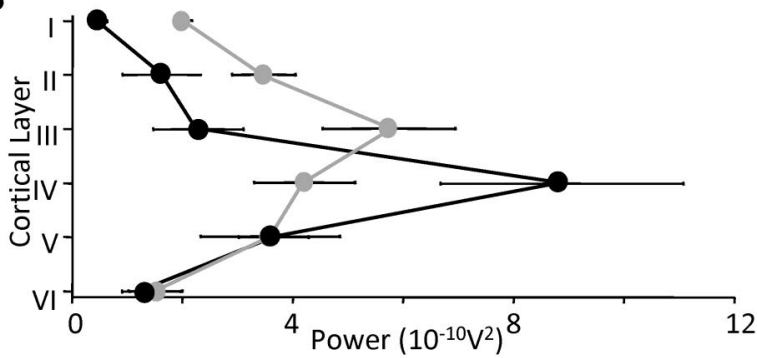

C
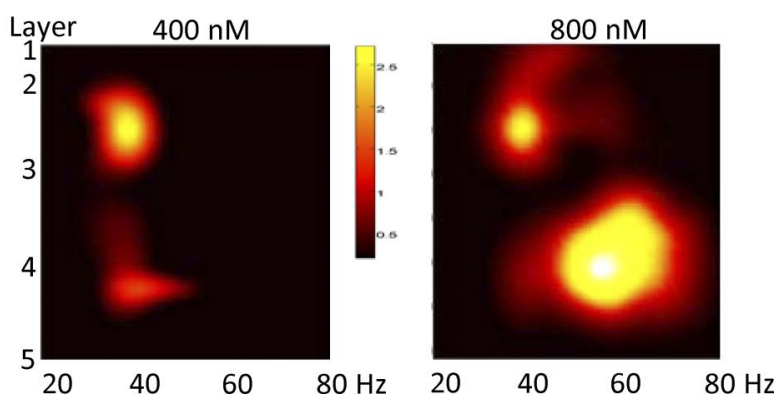

Figure 1. Increasing excitation to $\mathrm{A} 1$ induced lamina-specific frequency bifurcation of population gamma rhythms. Ai, Mean modal peak gamma rhythm power in population recordings from layer 4. As gamma power increases from 200 to $600 \mathrm{~nm}$, kainate frequency also increases. With kainate concentrations beyond $600 \mathrm{~nm}$, dual modal peaks are seen in the power spectra. Data shown as mean \pm SEM ( $n=6$ slices from 6 rats). Aii, Example pooled power spectra on either side of the bifurcation point ( $n=6$ slices from 6 rats) and corresponding single examples of population potentials below. Calibration: $200 \mu \mathrm{V}, 100 \mathrm{~ms}$. B, Laminar profile of peak gamma power in A1. Data shown as mean $\pm \operatorname{SEM}(n=6$ slices from 6 rats) for gamma generated by $800 \mathrm{~nm}$ kainate at peak frequencies of $30-45 \mathrm{~Hz}$ (gray lines and symbols) and $50-80 \mathrm{~Hz}$ (black lines and symbols). C, Power spectral density [mean ( $n=5$ slices from 5 rats) plotted as color map, in decibels] versus lamina and frequency within $\mathrm{A} 1$ before ( $400 \mathrm{~nm}$ kainate) and after ( 800 nm kainate) frequency bifurcation. Data shown taken from $1 \times 10$ linear array electrodes. Similar data were also obtained using parallel shanks on Utah probes but with lower spatial resolution.

values (Fig. 2A). Both rhythms were also significantly reduced by selective block of AMPA receptors with SYM2206 [required for persistent and PING rhythms but not ING rhythms (Whittington et al., 2011)]. However, the higher-frequency, layer 4 gamma rhythm was significantly less sensitive than the layer $2 / 3$ rhythm $(p<0.05, n=5$; Fig. $2 A)$.

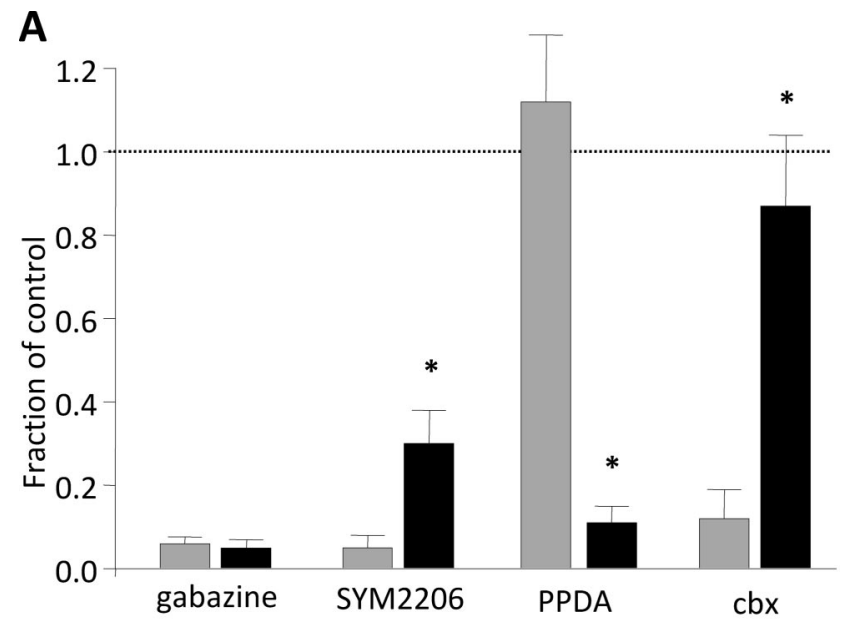

B
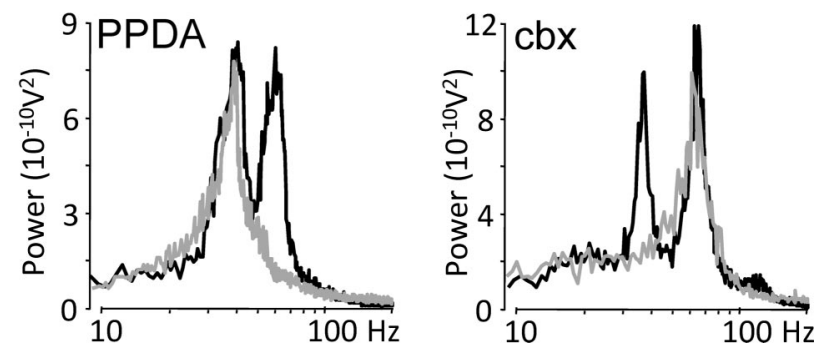

Figure 2. Pharmacological manipulation reveals different mechanisms underlying the slow and fast gamma rhythms. $\boldsymbol{A}$, Proportional change in mean ( $n=5$ slices from 5 rats) gamma power for slow, layer $2 / 3$ gamma $(30-45 \mathrm{~Hz}$, gray bars) and fast, layer 4 gamma $(50-80 \mathrm{~Hz}$, black bars), induced by $800 \mathrm{~nm}$ kainate. Both rhythms were equally sensitive to $\mathrm{GABA}_{\mathrm{A}}$ receptor blockade (gabazine, $1 \mu \mathrm{m}$ ). Layer 4, high gamma was significantly less sensitive to AMPA receptor blockade (SYM2206, $10 \mu \mathrm{M}$ ) and nonspecific gap junction conductance decrease [carbenoxolone (cbx), $0.2 \mathrm{~mm}$ [rsqb]. Layer 2/3, slow gamma was insensitive to NR2C/D-containing NMDAR blockade (PPDA, $10 \mu \mathrm{m}$ ), whereas this manipulation almost abolished layer 4, fast gamma. Asterisks indicate significantly different effects of each drug on the two gamma rhythms ( $p<0.05, n=5$ slices from 5 rats). $\boldsymbol{B}$, Example pooled power spectra ( $n=5$ slices from 5 rats) for layer 4 population responses to $800 \mathrm{~nm}$ kainate showing the differential effects of PPDA (left graph) and carbenoxolone (right graph).

Persistent gamma rhythm manifests mainly through increased axonal excitability and propagation of action potentials through an axonal plexus via non-chemical synaptic contacts (Traub et al., 2000). In contrast, the mechanisms underlying PING/interneuron network gamma rhythms (PING/ING) involve tonic excitation of interneuron and principal cell somata. PING rhythms in particular require strong excitation of principal cells, generating trains of orthodromic action potentials. We tested whether these two different mechanisms could account for the lower- and higherfrequency gamma rhythms, respectively. The main type of principal cell in layer 4 has a strong, near-tonic excitation mediated by NMDA receptors containing the NR2C subunit (Binshtok et al., 2006). Partially selective blockade of receptors containing this subunit with PPDA $(10 \mu \mathrm{M})$ almost abolished higher-frequency gamma power ( $88 \pm 6 \%$ decrease, $n=5, p<$ $0.05)$ but did not significantly alter power at the lower gamma frequency $(9 \pm 14 \%$ increase, $n=5, p>0.05$; Fig. $2 A)$. In contrast, partial reduction in gap junction conductance with carbenoxolone $(0.2 \mathrm{mM})$ showed the opposite selectivity for the two gamma rhythms. The higher-frequency gamma rhythm dominant in layer 4 was not significantly changed in power $(p>0.05$, $n=5$ ), but the layer $2 / 3$, lower-frequency gamma rhythm was reduced by $86 \pm 8 \%(p<0.05, n=5)$. 

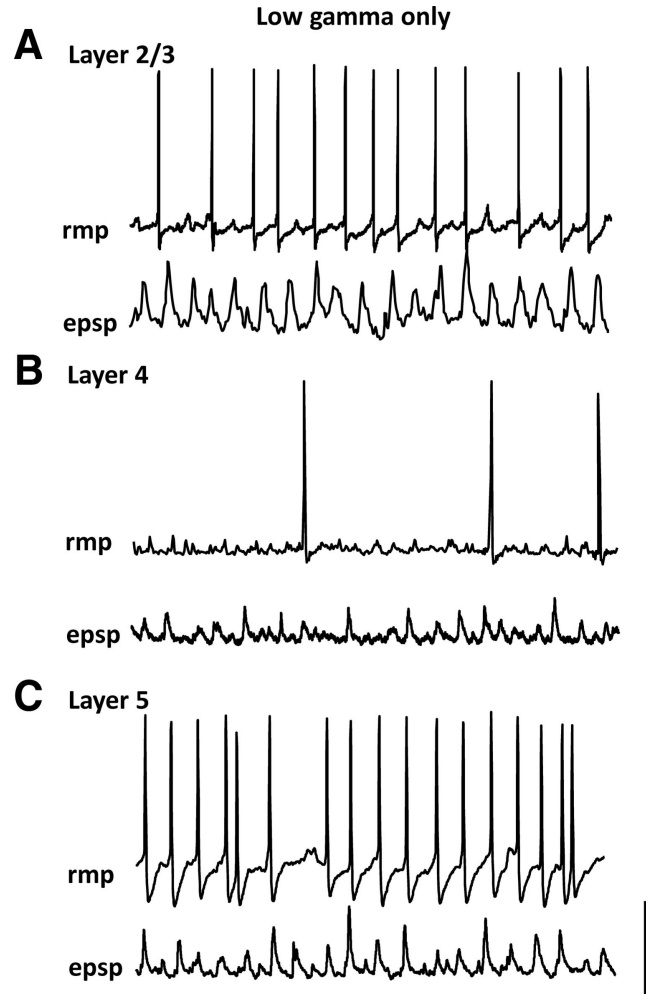

Low and high gamma
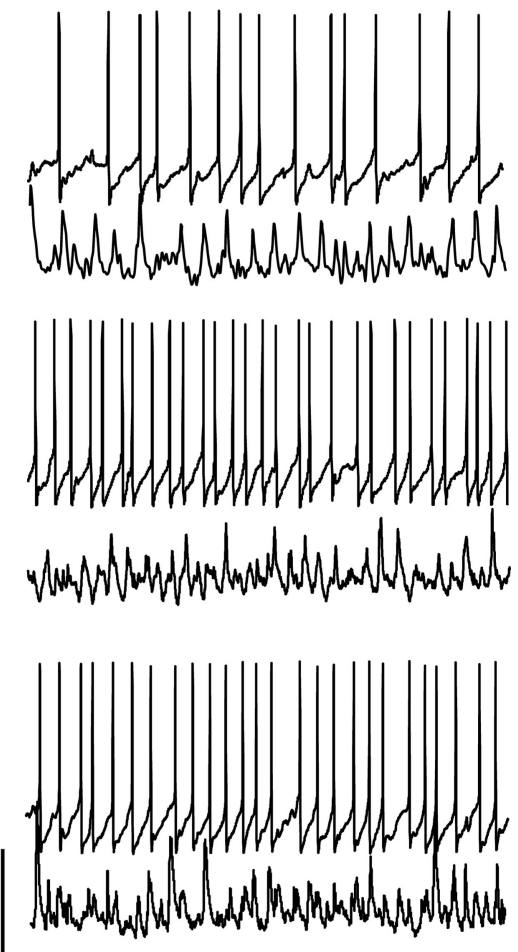

Figure 3. Lamina-specific interneuron input/output behavior before and after frequency bifurcation. $A$, Example layer $2 / 3 \mathrm{FS}$ interneuron recordings during exposure to $400 \mathrm{~nm}$ kainate (low gamma only) and $800 \mathrm{~nm}$ kainate (low and high gamma). Top traces show behavior at resting membrane potential (RMP) in each condition ( $-55 \mathrm{mV}$, low gamma only; $-53 \mathrm{mV}$, low and high gamma). Bottom traces show EPSP inputs recorded from $-70 \mathrm{mV}$ in each case. Note the maintenance of low gamma frequency spike generation despite the addition of faster, smaller EPSPs in the low and high gamma condition. $\boldsymbol{B}$, Example recordings from a layer $4 \mathrm{FS}$ interneuron during 400 and $800 \mathrm{~nm}$ kainate application, RMPs of -57 and $-52 \mathrm{mV}$, respectively. Bottom traces show EPSP inputs at $-70 \mathrm{mV}$. Note the paucity of spike generation and EPSP inputs in the low gamma condition is transformed into spiking at high gamma frequencies, with high gamma frequency EPSP inputs in $800 \mathrm{~nm}$ kainate. C, Example recordings from layer $5 \mathrm{FS}$ interneurons in the two conditions. RMPs were $-56 \mathrm{and}-54 \mathrm{mV}$. Note spike rates switch from low to high gamma frequency corresponding to an increase in rate of EPSPs from low to high gamma frequency. Calibration: $100 \mathrm{~ms}, 40 \mathrm{mV}$ (RMP), $10 \mathrm{mV}$ (EPSP).

\section{Interneuron input/output profile pre-frequency and post- frequency bifurcation are different in layers $2 / 3$ and 4}

Because both gamma rhythms were sensitive to $\mathrm{GABA}_{\mathrm{A}}$ receptor block, we examined the behavior of fast spiking (FS) interneurons (identified through step depolarizations and action potential/AHP properties) in the three main laminae. Before frequency bifurcation (400 nM kainate), FS interneurons in layers $2 / 3$ generated action potentials phase locked to the lower $(37 \pm 3 \mathrm{~Hz}$; Fig. $3 A$ ) frequency gamma rhythm with probabilities per field potential period of $0.75 \pm 0.11(n=5)$. In contrast, at $400 \mathrm{~nm}$ kainate, layer 4 FS cell spike output was weak. Spikes were phase locked to the lower gamma frequency field potential rhythm, but probabilities were low, $0.15 \pm 0.06$ (Fig. $3 B$ ), corresponding to a mean spike rate of $6 \pm 2 \mathrm{~Hz}$ during the $\sim 37 \mathrm{~Hz}$ population rhythm. This difference was reflected in the magnitude of phasic fast excitatory input received by each FS interneuron in each layer. Layer 2/3 FS cells received strong, compound EPSPs typical of persistent gamma rhythms (mean amplitude at $-70 \mathrm{mV}, 5.5 \pm$ $1.1 \mathrm{mV}$ ). The relatively quiescent layer $4 \mathrm{FS}$ cells had EPSPs of mean amplitude of $1.9 \pm 0.4 \mathrm{mV}$, significantly lower than seen for layer $2 / 3$ cells $(p<0.05, n=4)$.

After frequency bifurcation with $800 \mathrm{~nm}$ kainate, the behavior of layer 2/3 FS cells changed little. Spikes still occurred phase locked to the lower-frequency gamma rhythm, with a small but not significant increase in probability per field period $(0.80 \pm 0.12, p>0.05)$. EPSP inputs were still dominated by large compound events. However, an increase in smaller-amplitude EPSPs interspersed with the large compound events was seen. The result was an overall small decrease in mean EPSP size, with a significant increase in detected EPSP rate $(36 \pm 4 \mathrm{~Hz}$ with $400 \mathrm{~nm}$ kainate, $70 \pm 8 \mathrm{~Hz}$ with 800 nM kainate, $p<0.05$ ). Layer $2 / 3$ FS cell membrane potentials also changed little with increase in kainate concentration from 400 to $800 \mathrm{~nm}(-54 \pm 5 \mathrm{vs}-52 \pm 3$ $\mathrm{mV}, p>0.05, n=5)$ The main change after bifurcation came from the behavior of layer 4 FS cells. Spike output increased dramatically and became phase locked to the faster-frequency gamma rhythm and not the lower frequency. Probability of spiking per local field period approached 1.0 as EPSP inputs increased in amplitude (Fig. $3 B$ ). The largest change in input frequency was also seen for layer 4 FS cells. Here EPSP rates changed from $30 \pm 6 \mathrm{~Hz}$ (400 nM kainate) to $56 \pm 10 \mathrm{~Hz}(800 \mathrm{nM}$ kainate, $p<0.05$ ). In addition, a small but nonsignificant membrane potential depolarization was also seen in these FS cells $(-57 \pm 3 \mathrm{vs}-52 \pm 3 \mathrm{mV}, p>0.05, n=4)$.

\section{Principal cell behavior before and after bifurcation are different in layers $2 / 3$ and layer 4}

With a single gamma frequency evident in all layers during $400 \mathrm{~nm}$ kainate application, all principal cells recorded fired sparsely relative to the field potential frequency. In layer $2 / 3$ and layer 4 , spikes were always phase locked to the ongoing field low-frequency gamma rhythm (see Fig. $5 A$ ) but with similar low probabilities: layer 2/3 (Fig. $4 A$ ), $0.09 \pm 0.02$; layer 4 (Fig. $4 B), 0.05 \pm 0.02$. As with interneuron recordings, this profile of spike outputs did not change in layer $2 / 3$ principal cells after frequency bifurcation ( $800 \mathrm{~nm}$ kainate) but altered markedly in layer 4. Layer 4 spikes became phase locked to the faster gamma rhythm and occurred with a probability of $0.78 \pm 0.12$ per field gamma rhythm period (Fig. $4 B$ ).

Trains of fast inhibitory synaptic inputs reflected the layerspecific behavior of FS interneurons (Fig. 3). Large-amplitude IPSPs occurred at a peak frequency (from power spectra) corresponding to the field potential lower gamma frequency before and after bifurcation in layer $2 / 3$ (400 nM kainate, $35 \pm 5 \mathrm{~Hz} ; 800$ nM kainate $36 \pm 5 \mathrm{~Hz}$ ). No significant change in membrane potential was observed in these cells $(-64 \pm 4$ vs $-66 \pm 3 \mathrm{mV}, p>$ $0.05, n=5$ ). Layer 4 principal cells also received trains of IPSPs at the lower gamma frequency in $400 \mathrm{~nm}$ kainate (layer 4, $39 \pm 4 \mathrm{~Hz}$; layer $5,40 \pm 5 \mathrm{~Hz}, n=5$ ), despite a paucity of output from local, layer 4 interneurons (above). However, unlike principal cells in layer $2 / 3$, the frequency of inhibitory inputs changed significantly after gamma frequency bifurcation. Layer 4 principal cell IPSP rates increased to $62 \pm 8 \mathrm{~Hz}(p<0.05$ compared with before bifurcation, $n=5$ ), closely matching the now highly active local layer 4 interneuron output rates. In addition, layer 4 principal cells became significantly more tonically depolarized after 
bifurcation $(-65 \pm 4 \mathrm{vs}-57 \pm 3 \mathrm{mV}, \mathrm{p}<$ $0.05, n=5)$, suggestive of the establishment of a PING-like local layer 4 rhythm.

Additional evidence for a different source of synaptic inhibition underlying fast and slow gamma rhythms in each lamina was obtained from the kinetics of IPSPs in principal cells. In the presence of both 400 and $800 \mathrm{~nm}$ kainate, layer $2 / 3$ generated a slow gamma rhythm. In each case, principal cell IPSPs had relatively slow kinetics, with decay constants of $12 \pm 1$ and $11 \pm 3$ ms, respectively (Fig. 5). In contrast, activation of layer 4 to produce a faster local gamma rhythm with $800 \mathrm{~nm}$ kainate was associated with significantly sharper IPSPs. From low- to high-frequency gamma states, decay constants changed from $11 \pm$ 2 to $7 \pm 2 \mathrm{~ms}(n=4, p<0.05)$. A nearidentical switch to faster IPSPs was also seen in layer 5 principal cells when increasing kainate concentration from 400 to $800 \mathrm{~nm}$ (Fig. 5).

Layer 5 follows the fastest gamma frequency expressed in layer $2 / 3$ and layer 4

Both layer $2 / 3$ and layer 4 outputs converge on cortical layer 5 (Lefort et al., 2009), so we examined the effect of single and dual gamma rhythm generation on activity in this layer. Before bifurcation, with $400 \mathrm{~nm}$ kainate, FS interneurons in layer 5 generated action potentials phase locked to the only gamma rhythm manifest-the lower band $(37 \pm 3 \mathrm{~Hz}$; Fig. $3 C)$ —with spike probabilities per period of $0.86 \pm 0.18(n=4)$. Phasic EPSP inputs were evident but at lower mean amplitudes to those seen in layer $2 / 3(p<0.05, n=5)$, with faster decay times ( $7 \pm 3$ vs $12 \pm 3$ $\mathrm{ms}, p<0.05)$. After bifurcation, with $800 \mathrm{~nm}$ kainate, spikes in FS cells in layer 5 became phase locked to the faster frequency, layer 4 gamma rhythm and not the lower-frequency rhythm still manifest in layer $2 / 3$. Probability of spiking per local field period approached 1.0 as EPSP inputs increased in frequency and amplitude (Fig. 3C). A similar preference for the faster gamma rhythm was also seen in principal cells in layer 5. With a single, lower gamma frequency evident in all layers during $400 \mathrm{~nm}$ kainate application, layer 5 principal cells fired spikes or spike bursts sparsely relative to the field potential [see Figs. $4 C, 7 A$; probability of $0.07 \pm 0.03$ (counting a burst as a single event)]. After bifurcation, layer 5 principal cells also became phase locked to the faster rhythm, and spike probabilities increased to $0.45 \pm 0.10$ $(n=5$; see Figs. $4 C, 7 A)$.

\section{Principal cell spike rate and timing follow the faster gamma} rhythm in layers 4 and 5 but not layer $2 / 3$

Despite dramatic differences in spike rates in each layer, and pre-frequency and post-frequency bifurcation, correlation between spike timing and phase of the field gamma rhythm was always strong. In layer $2 / 3$ principal cells, field-triggered spike time histograms showed a tight probability maximum on the descending phase of each field period (see Fig. 7A), which did not
Low gamma only

Low and high gamma
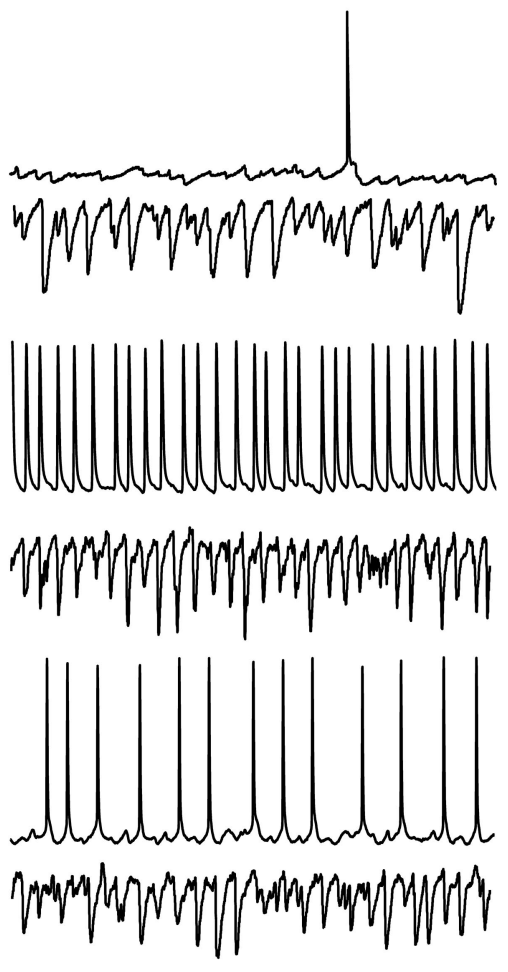

Figure 4. Lamina-specific principal cell input/output behavior before and after frequency bifurcation. $A$, Example layer $2 / 3$ regular spiking pyramidal cell recordings during exposure to $400 \mathrm{~nm}$ kainate (low gamma only) and $800 \mathrm{~nm}$ kainate (low and high priction, with RMPs of -64 and $-57 \mathrm{mV}$, respectively. Bottom traces show IPSP increase in mean IPSP amplitude in $800 \mathrm{~nm}$ kainate. C, Example recordings from a layer 5 intrinsically bursting pyramidal cell in the two conditions. RMPs were -67 and $-63 \mathrm{mV}$. Note that spike rates switch from sparse, with bursts, to a missed-beat pattern during $800 \mathrm{~nm}$ kainate. Note also the increase in rate of IPSPs in this cell type. Calibration: $100 \mathrm{~ms}, 30 \mathrm{mV}$ (RMP), $8 \mathrm{mV}$ (IPSP).

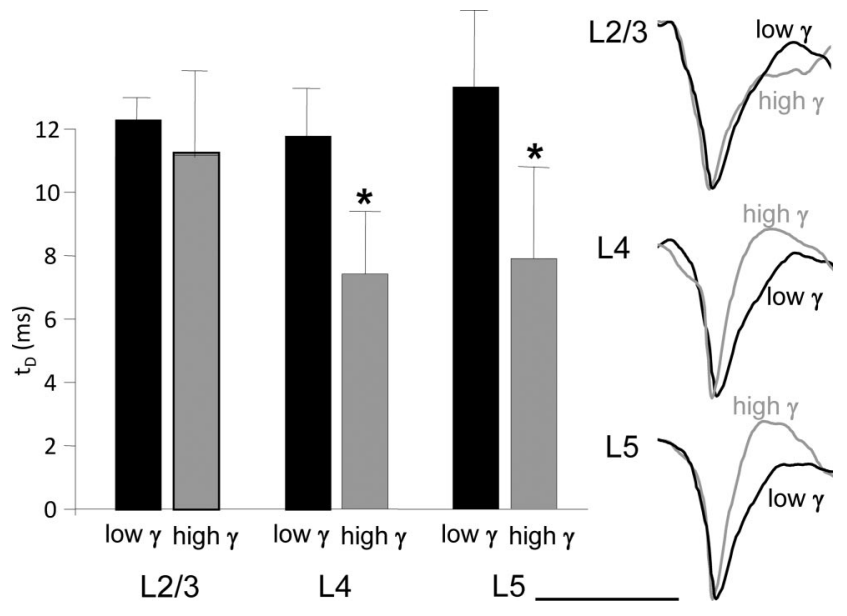

Figure 5. Higher gamma frequencies associate with faster pyramidal neuron IPSPs in layers 4 and 5 but not layer 2/3. Graph shows mean decay constants (single-exponential fit) for IPSPs (average of 50 IPSPs per principal cell subtype averaged over $n=5$ cells from 5 slices in each case) recorded from principal cells in each layer held at $-30 \mathrm{mV}$ by depolarizing current injection. Black bars show data in the presence of $400 \mathrm{~nm}$ kainate (low-frequency gamma only). Gray bars show data in the presence of $800 \mathrm{~nm}$ kainate (low- and higher-frequency gamma rhythms coexpressed). ${ }^{*} p<0.05$. Right shows example mean IPSPs from single neurons (IPSP amplitude maximum-referenced average of 50 events in each case). Black traces are taken in the presence of $400 \mathrm{~nm}$ kainate, gray traces in $800 \mathrm{~nm}$. Calibration: $20 \mathrm{~ms}$. 
A '400 nM kainate'
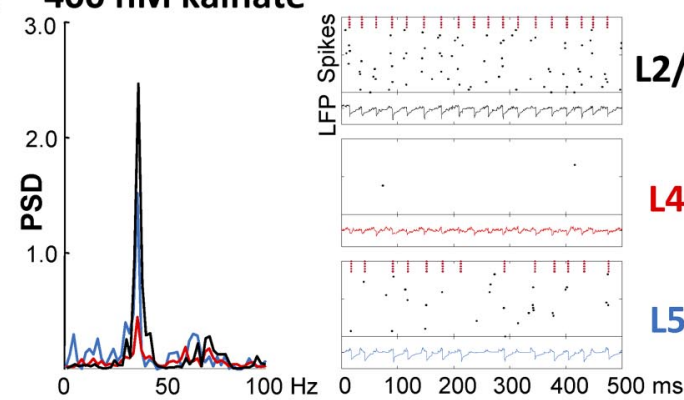

\section{'400 nM kainate' unconnected}

L2/3

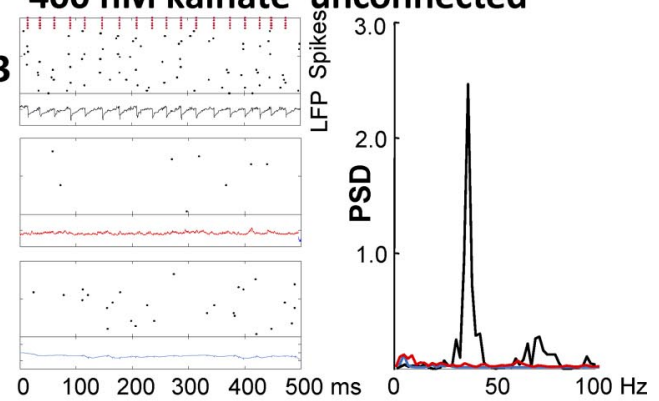

B ' $800 \mathrm{nM}$ kainate'

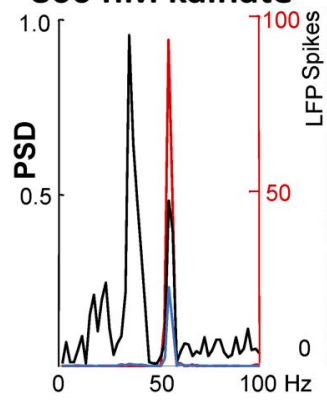

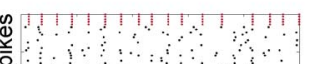
O

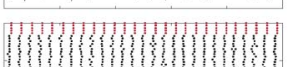

L4

\section{0 nM kainate' unconnected}

$L 2 / 3$

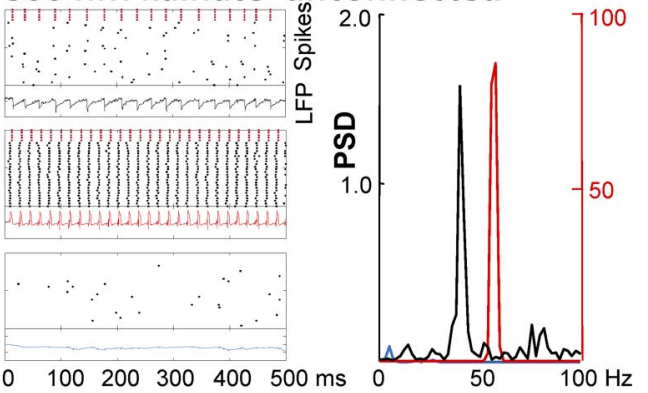

C

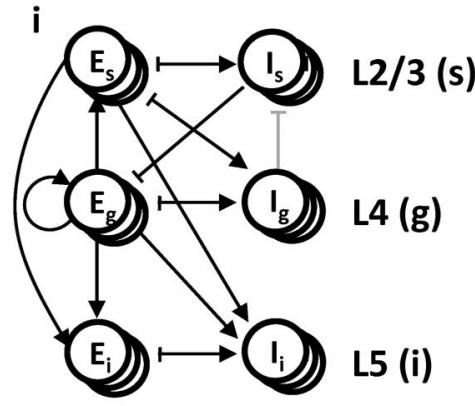

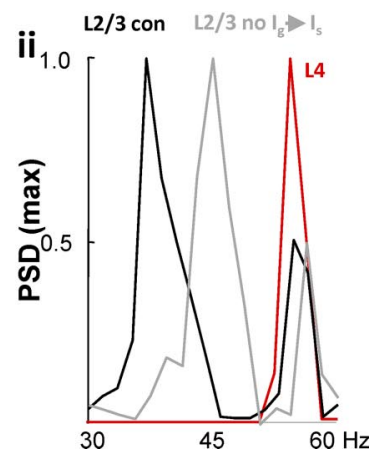

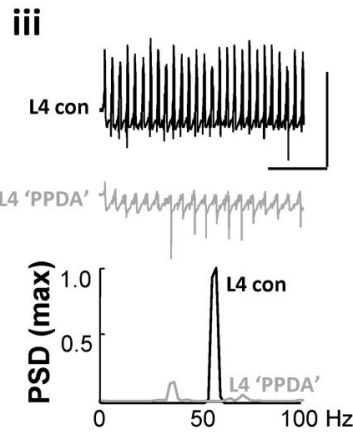

Figure 6. Computational model demonstrates laminar-specific frequency sensitivity with change in drive. $\boldsymbol{A}$, Behavior of the model network in conditions mimicking low glutamatergic excitation ( $400 \mathrm{~nm}$ kainate). The model robustly reproduces the core features of the experimental data: a low-frequency gamma rhythm in layers $2 / 3$ projected to layers 4 and 5 ; sparse spiking in principal cells; only interneuron recruitment in layers $2 / 3$ and 5 , abolished by uncoupling layers (right) (compare Figs. 3, 4). $\boldsymbol{B}$, Elevated tonic drive to layer 4 principal cells generates a faster rhythm in the model granular layer accompanied by local, intense principal cell spiking. Note that the lower-frequency, layer $2 / 3$ rhythm persists in the presence of this faster rhythm but at marginally lower power, but the layer 5 rhythm switches to the layer 4 input frequency. Each of these two effects is abolished with removal of interlaminar connections. Note the separate calibration bar (in red, right of PSD graphs) for power spectra from layer 4. Ci, Diagram showing the structure of the model (for details, see Materials and Methods). Cii, The frequency bifurcation is enhanced by interlaminar interactions. Model predicts the reduction in frequency seen at $800 \mathrm{~nm}$ kainate is in part generated by ascending inhibition onto superficial interneurons $\left(I_{g}-I_{s}\right.$ removed, gray spectrum). Ciii, Model shows that effects of PPDA can be attributed to reduction in $E_{g}-E_{g}$ recurrent excitation alone. Figure shows simulated field potentials from layer 4 in the presence (black) and absence (gray) of $E_{g}-E_{g}$ with NMDAR-like kinetics. Calibration: 0.2 V, $100 \mathrm{~ms}$. LFP, Local field potential.

appreciably alter before and after bifurcation. In each case, the spikes were phase locked to the slower frequency of the field potential gamma rhythms in layers $2 / 3$. In contrast, layer 4 and layer 5 principal cells phase locked always to the faster of the gamma rhythms evident, whether it be the layer $2 / 3$ rhythm (with low kainate concentrations) or the layer 4 rhythm with higher kainate concentrations. As a consequence, an increase in spike probability predicted an increase in network frequency: spiketriggered averaging of the local field potential exposed different spike-triggered waveform averages in the low-frequency gamma condition and the dual low- and high-frequency gamma condition (see Fig. 7A).

Additional evidence for the close correlation between spike rate and network frequency could be seen when considering instantaneous spike and field frequency in layer 4 (see Fig. $7 B$ ). When a single, lower-frequency gamma rhythm was the only modal peak in the spectrum layer 4 principal cell spiked with similar or, more commonly, lower frequencies than those seen in the field. However, after frequency bifurcation, there was a near 1:1 relationship between layer 4 interspike interval and the concurrently recorded field potential gamma period duration. These data, and the pattern of IPSPs and EPSPs seen in principal cells and interneurons, respectively, strongly suggest that the faster gamma rhythm was generated by a predominantly PING-like mechanism involving local circuits in layer 4 .

\section{The gamma frequency bifurcation has consequences for interlaminar synchrony}

Gamma rhythms facilitate inter-areal communication in cortex in vivo (Fries, 2005). The ability of different laminae to act as generators for different frequencies of gamma rhythm in a single primary sensory area suggests that interlaminar communication may also be controllable through gamma rhythms. We used multi-electrode arrays to concurrently record field potentials in 
A1 to test this. Peak cross-correlation values were calculated relative to layer 5 activity because layer 5 receives inputs from both layer 2/3 and layer 4 (Watts and Thomson, 2005; Lefort et al., 2009). With 400 nm kainate drive (generating only a single lowerfrequency gamma rhythm), layer 5 field activity was correlated most with field activity in layer $2 / 3$ and not layer 4 (see Fig. 8). Peak correlation values between local field potentials were seen for electrodes in upper layer $3(0.72 \pm 0.11, n=5)$, with a mean phase lead of $3.2 \pm 0.8 \mathrm{~ms}$, suggesting, alongside the intracellular data (Figs. 3, 4), that layer 5 activity during lower-frequency gamma rhythms was not generated locally but projected from layer $2 / 3$. When cortex was excited with $800 \mathrm{~nm}$ kainite, the correlation profile changed. In the presence of a superficial lower gamma frequency and a higher gamma frequency in layers 4 and 5 , layer 5 activity correlated best with activity in layer 4 , not layer $2 / 3$. Maximal correlation values in layer 4 were $0.57 \pm 0.12$, with a mean phase lead of $1.4 \pm 0.3 \mathrm{~ms}$. These data suggest that activation of the layer 4 gamma generator actively impedes the influence of ongoing gamma rhythms from layer $2 / 3$ on cortical output via layer 5 .

\section{Model produces properties of distinct laminar gamma generators and predicts mechanisms of interaction}

The persistent gamma rhythm in layer $2 / 3$ was modeled by changing the Poisson rate of stochastic excitatory inputs to the supragranular layer $2 / 3$ excitatory cells. In the model of the 400 nM kainate condition, a Poisson rate of $65 \mathrm{~Hz}$ for these noisy inputs resulted in a layer $2 / 3$ oscillation of $36 \mathrm{~Hz}$, which was only slightly affected by the presence of interlaminar connections (Fig. $6 A)$. In these simulations, the mean excitatory cell spike output frequency was $6.3 \mathrm{~Hz}$ for the layer $2 / 3$ cells, consistent with the experimental observation that these cells exhibit low spiking frequencies relative to the field frequency.

Layers 4 and 5 also exhibited $36 \mathrm{~Hz}$ rhythms in the $400 \mathrm{~nm}$ kainate conditions, although they were generated by different mechanisms in the model. The layer 4 rhythm existed despite the absence of an intrinsic active gamma-generating network at this level of excitability. Only a few random $E_{g}$ cell spikes persisted, and there was no $I_{g}$ cell spiking activity (Fig. $6 A$ ). The layer 4 rhythm was produced by the presence of a feedback $I_{s}-E_{g}$ connection from layer $2 / 3$; removal of this connection resulted in the absence of the $36 \mathrm{~Hz}$ rhythm in layer 4 (data not shown). In contrast, the layer 5 rhythm was qualitatively similar to that found in layer $2 / 3$. The $E_{s}-E_{i}$ connection was necessarily weak to replicate the low spike probabilities observed in layer 5 principal cells, with a mean spike rate of $2.3 \mathrm{~Hz}$ in the $E_{i}$ cells. Therefore, the $E_{s}-I_{i}$ connection was the primary contributor to the lowfrequency rhythm observed in the layer 5 model.

In the model of $800 \mathrm{~nm}$ kainate, the measured layer $2 / 3$ frequency at $34 \mathrm{~Hz}$ appeared similar to the $400 \mathrm{~nm}$ kainate condition, whereas $54 \mathrm{~Hz}$ rhythms were now present in layers 4 and 5 (Fig. 6B). However, the low-frequency rhythm in layer $2 / 3$ was influenced by interlaminar connections especially dependent on feedforward inhibition from layer 4. To model the $800 \mathrm{~nm}$ kainate condition in layer 4 , a strong tonic drive was applied to $E_{g}$ cells, and the Poisson rate to the $E_{s}$ cells was increased to $80 \mathrm{~Hz}$. The mean firing frequency was $54 \mathrm{~Hz}$ for $E_{g}$ cells in layer 4 and $14 \mathrm{~Hz}$ for $E_{s}$ cells in layer $2 / 3$, replicating the experimentally observed differences between the persistent gamma rhythm in layer $2 / 3$ and the PING rhythm in layer 4 . Removal of all interlaminar connections resulted in a layer 4 frequency of $58 \mathrm{~Hz}$ and a layer $2 / 3$ frequency of $40 \mathrm{~Hz}$, demonstrating that the networks had a higher baseline excitability than the $400 \mathrm{~nm}$ simulations; they
A
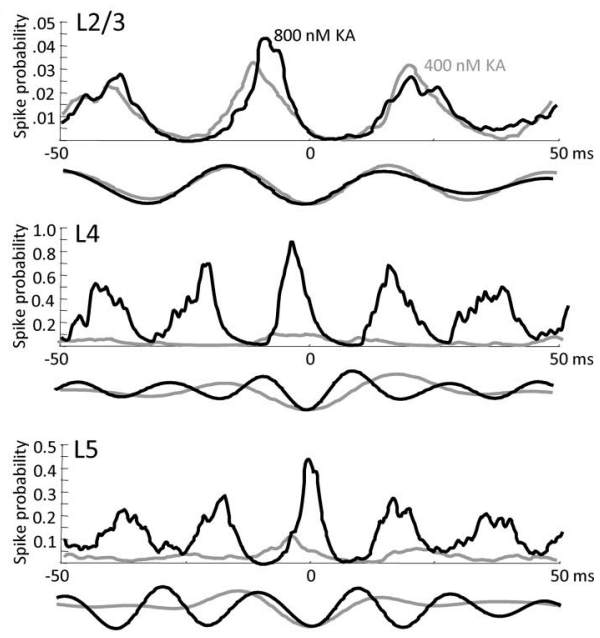

B

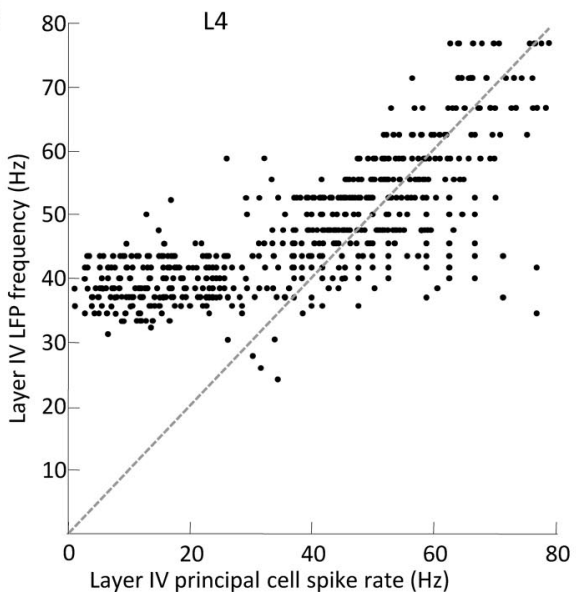

Figure 7. Layers 4 and 5 but not layer $2 / 3$ principal cells phase lock to the faster gamma rhythm. $A$, Graphs showing mean ( $n=5$ cells from 5 slices each from a separate rat) spike probability for layer 2/3 (top), layer 4 (middle), and layer 5 (bottom) principal cells. Data are plotted as probability of observing a spike on any given gamma period relative to local field potential phase in $1 \mathrm{~ms}$ bins, with $0 \mathrm{~ms}$ being the peak negativity in the field on each period. Data are overlaid from the two kainate (KA) concentrations: $400 \mathrm{~nm}$ generating only the lower gamma frequency (gray line) and $800 \mathrm{~nm}$ generating both fast and slow gamma rhythms concurrently (black line). Mean example traces below show $100 \mathrm{~ms}$ epochs of local field potential averaged to each spike in the corresponding intracellular recording. Note the different probability values on the axes for each of the three principal cell types. $\boldsymbol{B}$, Period-by-period analysis of the relationship between instantaneous layer 4 local field potential frequency and corresponding layer 4 principal cell spiking. Data are pooled for both 400 and $800 \mathrm{~nm}$ kainate conditions. Note the near 1:1 relationship between layer 4 principal cell spike rate and field potential frequency for gamma frequencies over $\sim 45 \mathrm{~Hz}$.

were not already firing at the frequencies observed in the connected network (data not shown). The separation of frequencies was found to depend on the feedforward $I_{g}-I_{s}$ connection from layer 4 to layer $2 / 3$. Although this connection did not play a role at low excitability in the model $\left(I_{g}\right.$ cells were not activated; see above and Fig. $6 \mathrm{~B}$ ), removal of this $I_{g}-I_{s}$ connection increased the layer $2 / 3$ frequency from 34 to $42 \mathrm{~Hz}$ under high kainate model conditions (Fig. 6Cii). The interlaminar connections between the two gamma-generating networks in the model served to increase the frequency separation between the layer-specific rhythms in the high kainate condition.

To generate the layer 5 rhythm, a moderately strong $E_{g}-E_{i}$ connection was necessary to override the effects of layer $2 / 3$ on layer 5 . The resulting layer 5 rhythm was different from the layer 4 rhythm, despite sharing the same $54 \mathrm{~Hz}$ frequency. In contrast to the $54 \mathrm{~Hz}$ 
A

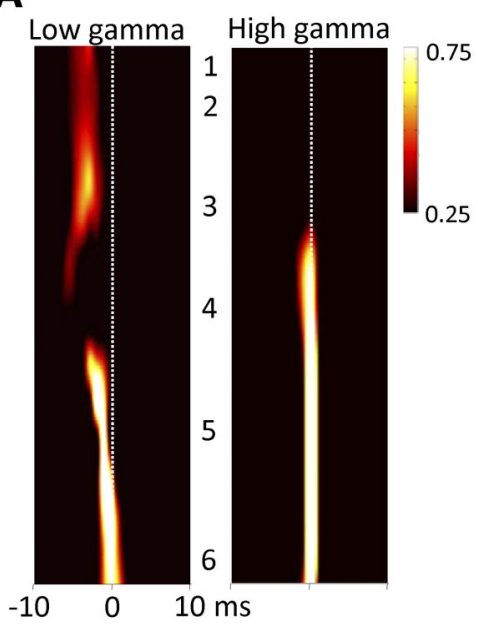

B

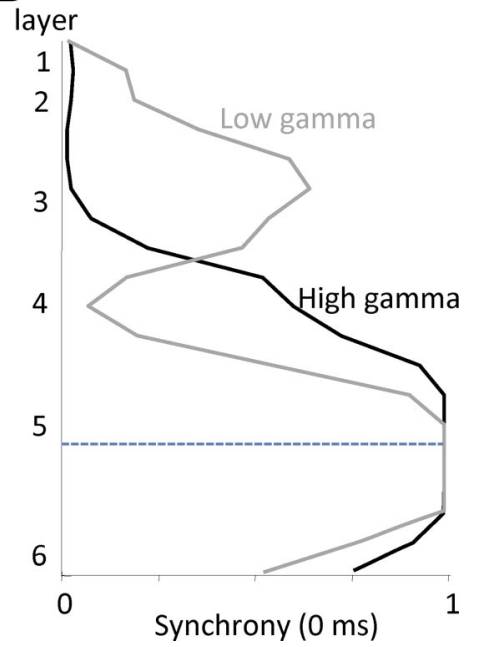

Figure 8. The generation of the higher gamma frequency rhythm in layer 4 switches interlaminar synchrony relative to the layer 5 local field potential. $\boldsymbol{A}$, Plots of field potential cross-correlation values (as color map) against phase and layer. Reference in each case was mid-layer 5 electrode. Note the contrasting interlaminar interactions in the presence of a single low gamma rhythm (400 nм kainate, left) and high and low gamma rhythms ( 800 nm kainate, right). $\boldsymbol{B}$, Plot of mean, maximal synchrony within a \pm 5 -mswide bin centered around 0 ms from cross-correlations with layer 5 as reference. Note that layer 5 synchronizes preferentially with layer 2/3 in the low gamma condition ( $400 \mathrm{~nm}$ kainate, gray line) but layer 4 in the high and low gamma condition ( 800 nm kainate, black line).

mean spike rates observed in $E_{g}$ cells of layer 4 , the $E_{i}$ cells in layer 5 had a mean frequency of $22 \mathrm{~Hz}$ (compare Fig. $6 B$ ), consistent with the experimental observations.

To model the effect of PPDA in layer 4 at $800 \mathrm{~nm}$ kainate, $E_{g}-E_{g}$ connections were removed in the model, which resulted in a decrease in the layer 4 frequency from 54 to $36 \mathrm{~Hz}$. Although this appeared to suggest that the low-frequency gamma rhythm from layer $2 / 3$ in $400 \mathrm{~nm}$ kainate conditions remained, the low-frequency rhythm in layer 4 exhibited $33 \mathrm{~Hz}$ mean spike rates in the PPDA simulations compared with nearly zero in the $400 \mathrm{~nm}$ kainate simulations. The model therefore predicts that the low-frequency rhythm observed in layer 4 with $800 \mathrm{~nm}$ kainate and PPDA is accompanied by higher individual excitatory cell spike rates than at $400 \mathrm{~nm}$ kainate. Additional experiments will be required to test the prediction that these two low-frequency gamma rhythms are mechanistically distinct, despite being similar in frequency.

Finally, removal of the slow potassium M-like current in layer $2 / 3$ in these simulations increased the baseline excitability of the layer $2 / 3$ network, shifting the frequency from 36 to $48 \mathrm{~Hz}$. In the $800 \mathrm{~nm}$ kainate condition, removal of the M-like current increased the frequency of the layer $2 / 3$ network similarly, from 34 to $48 \mathrm{~Hz}$, even as the layer 4 network frequency remained the same (data not shown).

\section{Discussion}

In A1 in vitro, the present results reveal two independent, local gamma generators. The rhythms were of different frequency, $30-45$ and $50-80 \mathrm{~Hz}$, and originated in layer $2 / 3$ and layer 4 , respectively. The higher-frequency rhythm was seen only with increased drive-induced bifurcation of the spectrum within the gamma band. Simulations suggested that this frequency separation was facilitated by inhibitory interlaminar connections (Kätzel et al., 2011). Layer 5 oscillated phase and frequency locked to the faster rhythm present, suggesting a "winner-take-all" competition between layers for control over the dynamics of auditory cortical output. The drive used in this study increases both

axonal and somatodendritic excitability (Whittington et al., 2011), mimicking the activated state of neocortex (Cunningham et al., 2006). The changes in gamma frequency with this drive have similarities to in vivo studies with changes in sensory stimuli (Ray et al., 2008), suggesting that output from sensory areas may be dramatically influenced by relative stimulus intensity. Furthermore, the stimulus (drive) dependence of only one of these gamma rhythms suggests a possible substrate for broadband gamma responses, particularly with averaging across many sensory trials (Le Van Quyen et al., 2010).

Multiple local circuits can temporally interact if they generate oscillations at a single frequency (Traub et al., 1996a; Fries, 2005), even when one oscillator is broadly tuned (Gregoriou et al., 2009). This temporal interaction has cognitive significance (Fries, 2005). In these cases, the combination of distal feedforward and local feedback inhibition provides a robust mechanism for synchrony (Traub et al., 1996a). However, a number of reports indicate different cognitive processes associating with different gamma frequencies (Vidal et al., 2006; Kaiser et al., 2008; Wyart and Tallon Baudry, 2008; Herrmann et al., 2010). The present data from A1 and data from visual cortex (Oke et al., 2010) show that gamma rhythm generators with different frequencies may coexist in different laminae of the same cortical area. How might such multiple frequency channels be concurrently maintained?

There is much interlaminar connectivity in neocortex, so it is surprising that generators of different frequencies can coexist (Roopun et al., 2008). However, the different mechanisms of layer $2 / 3$ and layer 4 gamma rhythms may help in understanding this. In layer $2 / 3$, the gamma rhythm was of the "persistent" subtype demonstrated previously as a consequence of axonal rather than somatic spike generation (Cunningham et al., 2004; Traub et al., 2005). The resulting axonal noise provides an intense phasic synaptic drive to interneurons (Whittington and Traub, 2003), which in turn generates a low gamma band rhythm that is relatively inert to changes in drive (Whittington et al., 2011). Thus, any change in excitatory input to layer $2 / 3$ [from active layer 4 principal cells (Lefort et al., 2009)] is unlikely to markedly affect supragranular network frequency as seen here. This suggests that the intercortical interactions seen in vivo at low gamma frequency, and with few somatic spikes (Miller, 1996), may represent activity in superficial layers predominantly.

In contrast, PING-like gamma rhythms require high somatic principal cell spike rates (Fig. 7B; Traub et al., 1996b), and somatodendritic excitation is a direct determinant of network frequency (Kopell et al., 2000). With higher drives, this excitation appeared to be mediated by the layer 4 recurrent network (Lefort et al., 2009) using NMDA receptors (Binshtok et al., 2006). The resulting gamma frequency was highly sensitive to the degree of excitation. Different intensities of cortical input (excitation to layer 4), corresponding to different components of a complex sensory stimulus, may therefore drive subsets of layer 4 principal cells at different frequencies (Kaiser et al., 2008). Such a scenario may generate a near-continuous range of gamma frequencies 
with highly complex stimuli, such as natural scenes (Uhlhaas et al., 2011).

With low levels of feedback excitation from layer $2 / 3$ to layer 4 , activation within layer 4 can generate a faster, more frequencylabile gamma rhythm with little interference from layer $2 / 3$. This was suggested by model results, in which increasing $E_{s}-I_{g}$ did not change the frequency of the layer 4 rhythm. It may seem that layer 4 does not affect layer $2 / 3$ because, after bifurcation, layer $2 / 3$ gamma was similar in frequency to that seen with a single gamma rhythm in low concentrations of kainate. However, the model results show that this can be a consequence of the balance of feedforward inhibition and excitation from layer 4 up to layer $2 / 3$ (Fig. 6Ci). Within this scheme, weak inputs to layer 4 are likely to be modified by ongoing activity in layers $2 / 3$ before influencing output layer 5 , with the low-frequency gamma rhythm in layer 4 being a consequence of inhibition from layer $2 / 3$. In contrast, strong inputs to layer 4 provide dynamic environment that "ignores" layer $2 / 3$ (Fig. 8), allowing input into layer 4 to directly influence layer 5 and thus cortical output. Both layer $2 / 3$ and layer 5 have characteristic patterns of horizontal connectivity (Reid et al., 2009). Thus, different levels of excitation allow the anatomical segregation of layers and their projections to be complemented by temporal segregation of the signals they carry.

Neuromodulation may also influence interlaminar interactions. In the model simulations, removal of M-current increased excitability in the layer $2 / 3$ network, resulting in a greater field and spike frequency in that layer with higher drives (Börgers et al., 2005), whereas the layer 4 frequency was maintained. Such changes of frequency are important because different rhythms may positively or negatively interact depending on their frequency ratios (Roopun et al., 2008). Thus, the ability of cholinergic neuromodulation and stimulus (drive) strengths to differentially affect the two gamma generators may, in part, explain the different reported effects of attention [modulated by muscarinic drive (Herrero et al., 2008)] on gamma power (decrease or increase: Fries et al., 2001; Chalk et al., 2010) and higherfrequency gamma "suppression" or enhancement during task performance depending on cortical subregion studied (Shmuel et al., 2006; Hayden et al., 2009; Jerbi et al., 2010).

In summary, the gamma rhythm in $\mathrm{A} 1$ is not a homogeneous entity. Excitation to layer 4 splits the rhythm into two distinct frequencies associated with different spike patterns (sparse and rate coded). Model results suggested that the interlaminar inhibition may be important in establishing this split. The competition between the two rhythms for temporal control of layer 5 suggests a dynamic system designed specifically to generate and use frequency bifurcation as a means to code intensity in auditory sensory input.

\section{References}

Atencio CA, Schreiner CE (2010) Columnar connectivity and laminar processing in cat primary auditory cortex. PLoS One 5:e9521.

Binshtok AM, Fleidervish IA, Sprengel R, Gutnick MJ (2006) NMDA receptors in layer 4 spiny stellate cells of the mouse barrel cortex contain the NR2C subunit. J Neurosci 26:708-715.

Börgers C, Epstein S, Kopell NJ (2005) Background gamma rhythmicity and attention in cortical local circuits: a computational study. Proc Natl Acad Sci U S A 102:7002-7007.

Chalk M, Herrero JL, Gieselmann MA, Delicato LS, Gotthardt S, Thiele A (2010) Attention reduces stimulus-driven gamma frequency oscillations and spike field coherence in V1. Neuron 66:114-125.

Compte A, Sanchez-Vives MV, McCormick DA, Wang XJ (2003) Cellular and network mechanisms of slow oscillatory activity $(<1 \mathrm{~Hz})$ and wave propagations in a cortical network model. J Neurophysiol 89:2707-2725.

Crone NE, Miglioretti DL, Gordon B, Lesser RP (1998) Functional mapping of human sensorimotor cortex with electrocorticographic spectral analysis. II. Event-related synchronization in the gamma band. Brain 121: 2301-2315.

Crone NE, Sinai A, Korzeniewska A (2006) High-frequency gamma oscillations and human brain mapping with electrocorticography. Prog Brain Res 159:275-295.

Cunningham MO, Halliday DM, Davies CH, Traub RD, Buhl EH, Whittington MA (2004) Coexistence of gamma and high-frequency oscillations in rat medial entorhinal cortex in vitro. J Physiol 559:347-353.

Cunningham MO, Pervouchine DD, Racca C, Kopell NJ, Davies CH, Jones RS, Traub RD, Whittington MA (2006) Neuronal metabolism governs cortical network response state. Proc Natl Acad Sci U S A 103:5597-5601.

Edwards E, Soltani M, Deouell LY, Berger MS, Knight RT (2005) High gamma activity in response to deviant auditory stimuli recorded directly from human cortex. J Neurophysiol 94:4269-4280.

Engel AK, Singer W (2001) Temporal binding and the neural correlates of sensory awareness. Trends Cogn Sci 5:16-25.

Engel AK, Fries P, Singer W (2001) Dynamic predictions: oscillations and synchrony in top-down processing. Nat Rev Neurosci 2:704-716.

Fries P (2005) A mechanism for cognitive dynamics: neuronal communication through neuronal coherence. Trends Cogn Sci 9:474-480.

Fries P, Reynolds JH, Rorie AE, Desimone R (2001) Modulation of oscillatory neuronal synchronisation by selective visual attention. Science 291:1560-1563.

Gillies MJ, Traub RD, LeBeau FE, Davies CH, Gloveli T, Buhl EH, Whittington MA (2002) A model of atropine-resistant theta oscillations in rat hippocampal area CA1. J Physiol 543:779-793.

Gloveli T, Dugladze T, Saha S, Monyer H, Heinemann U, Traub RD, Whittington MA, Buhl EH (2005) Differential involvement of oriens/pyramidale interneurones in hippocampal network oscillations in vitro. J Physiol 562:131-147.

Gregoriou GG, Gotts SJ, Zhou H, Desimone R (2009) High-frequency, long-range coupling between prefrontal and visual cortex during attention. Science 324:1207-1210.

Hayden BY, Smith DV, Platt ML (2009) Electrophysiological correlates of default-mode processing in macaque posterior cingulate cortex. Proc Natl Acad Sci U S A 106:5948-5953.

Herrero JL, Roberts MJ, Delicato LS, Gieselmann MA, Dayan P, Thiele A (2008) Acetylcholine contributes through muscarinic receptors to attentional modulation in V1. Nature 454:1110-1114.

Herrmann CS, Fründ I, Lenz D (2010) Human gamma-band activity: a review on cognitive and behavioral correlates and network models. Neurosci Biobehav Rev 34:981-992.

Jerbi K, Ossandón T, Hamamé CM, Senova S, Dalal SS, Jung J, Minotti L, Bertrand O, Berthoz A, Kahane P, Lachaux JP (2009) Task-related gamma-band dynamics from an intracerebral perspective: review and implications for surface EEG and MEG. Hum Brain Mapp 30:1758-1771.

Jerbi K, Vidal JR, Ossandon T, Dalal SS, Jung J, Hoffmann D, Minotti L, Bertrand O, Kahane P, Lachaux JP (2010) Exploring the electrophysiological correlates of the default-mode network with intracerebral EEG. Front Syst Neurosci 4:27.

Kaiser J, LutzenbergerW (2005) Cortical oscillatory activity and the dynamics of auditory memory processing. Rev Neurosci 16:239-254.

Kaiser J, Heidegger T, Wibral M, Altmann CF, Lutzenberger W (2008) Distinct gamma-band components reflect the short-term memory maintenance of different sound lateralization angles. Cereb Cortex 18:2286-2295.

Kätzel D, Zemelman BV, Buetfering C, Wölfel M, Miesenböck G (2011) The columnar and laminar organisation of inhibitory connections to neocortical excitatory cells. Nat Neurosci 14:100-107.

Kopell N, Ermentrout GB, Whittington MA, Traub RD (2000) Gamma rhythms and beta rhythms have different synchronization properties. Proc Natl Acad Sci U S A 97:1867-1872.

Kudoh M, Seki K, Shibuki K (2004) Sound sequence discrimination learning is dependent on cholinergic inputs to the rat auditory cortex. Neurosci Res 50:113-123.

Lachaux JP, George N, Tallon-Baudry C, Martinerie J, Hugueville L, Minotti L, Kahane P, Renault B (2005) The many faces of the gamma band response to complex visual stimuli. Neuroimage 25:491-501.

Le Van Quyen M, Staba R, Bragin A, Dickson C, Valderrama M, Fried I, Engel J (2010) Large-scale microelectrode recordings of high-frequency 
gamma oscillations in human cortex during sleep. J Neurosci 30: $7770-7782$.

Lefort S, Tomm C, Floyd Sarria JC, Petersen CC (2009) The excitatory neuronal network of the $\mathrm{C} 2$ barrel column in mouse primary somatosensory cortex. Neuron 61:301-316.

Mainen ZF, Sejnowski TJ (1996) Influence of dendritic structure on firing pattern in model neocortical neurons. Nature 382:363-366.

McCarthy MM, Brown EN, Kopell N (2008) Potential network mechanisms mediating electroencephalographic beta rhythm changes during propofol-induced paradoxical excitation. J Neurosci 28:13488-13504.

Middleton S, Jalics J, Kispersky T, Lebeau FE, Roopun AK, Kopell NJ, Whittington MA, Cunningham MO (2008) NMDA receptor-dependent switching between different gamma rhythm-generating microcircuits in entorhinal cortex. Proc Natl Acad Sci U S A 105:18572-18577.

Miller R (1996) Neural assemblies and laminar interactions in the cerebral cortex. Biol Cybern 75:253-261.

Oke OO, Magony A, Anver H, Ward PD, Jiruska P, Jefferys JG, Vreugdenhil M (2010) High-frequency gamma oscillations coexist with lowfrequency gamma oscillations in the rat visual cortex in vitro. Eur J Neurosci 31:1435-1445.

Pettersen KH, Devor A, Ulbert I, Dale AM, Einevoll FT (2006) Currentsource density estimation based on inversion of electrostatic forward solution: effects of finite extent of neuronal activity and conductivity discontinuities. J Neurosci Methods 154:116-133.

Pipa G, Städtler ES, Rodriguez EF, Waltz JA, Muckli LF, Singer W, Goebel R, Munk MH (2009) Performance- and stimulus-dependent oscillations in monkey prefrontal cortex during short-term memory. Front Integr Neurosci 3:25.

Rasch MJ, Gretton A, Murayama Y, Maass W, Logothetis NK (2008) Inferring spike trains from local field potentials. J Neurophysiol 99:1461-1476.

Ray S, Hsiao SS, Crone NE, Franaszczuk PJ, Niebur E (2008) Effect of stimulus intensity on the spike-local field potential relationship in the secondary somatosensory cortex. J Neurosci 28:7334-7343.

Reid AT, Krumnack A, Wanke E, Kötter R (2009) Optimization of cortical hierarchies with continuous scales and ranges. Neuroimage 47:611-617.

Roopun AK, Kramer MA, Carracedo LM, Kaiser M, Davies CH, Traub RD, Kopell NJ, Whittington MA (2008) Period concatenation underlies interactions between gamma and beta rhythms in neocortex. Front Cell Neurosci 2:1.

Rubin JE, Terman D (2004) High frequency stimulation of the subthalamic nucleus eliminates pathological thalamic rhythmicity in a computational model. J Comput Neurosci 16:211-235.

Saito Y, Mitsui T (1993) Simulation of stochastic differential equations. Ann Inst Statist Math 45:419-432.

Shmuel A, Augath M, Oeltermann A, Logothetis NK (2006) Negative func- tional MRI response correlates with decreases in neuronal activity in monkey visual area V1. Nat Neurosci 9:569-577.

Siegel M, König P (2003) A functional gamma-band defined by stimulusdependent synchronization in area 18 of awake behaving cats. J Neurosci 23:4251-4260.

Thomson AM, Bannister AP (2003) Interlaminar connections in the neocortex. Cereb Cortex 13:5-14.

Tiesinga PH, José JV, Sejnowski TJ (2000) Comparison of current-driven and conductance-driven neocortical model neurons with HodgkinHuxley voltage-gated channels. Phys Rev E Stat Phys Plasmas Fluids Relat Interdiscip Topics 62:8413-8419.

Traub RD, Whittington MA, Stanford IM, Jefferys JG (1996a) A mechanism for generation of long-range synchronous fast oscillations in the cortex. Nature 383:621-624.

Traub RD, Whittington MA, Colling SB, Buzsáki G, Jefferys JG (1996b) Analysis of gamma rhythms in the rat hippocampus in vitro and in vivo. J Physiol 493:471-484.

Traub RD, Bibbig A, Fisahn A, LeBeau FE, Whittington MA, Buhl EH (2000) A model of gamma-frequency network oscillations induced in the rat CA3 region by carbachol in vitro. Eur J Neurosci 12:4093-4106.

Traub RD, Whittington MA, Buhl EH, LeBeau FE, Bibbig A, Boyd S, Cross H, Baldeweg T (2001) A possible role for gap junctions in generation of very fast EEG oscillations preceding the onset of, and perhaps initiating, seizures. Epilepsia 42:153-170.

Traub RD, Bibbig A, LeBeau FE, Cunningham MO, Whittington MA (2005) Persistent gamma oscillations in superficial layers of rat auditory neocortex: experiment and model. J Physiol 562:3-8.

Uhlhaas PJ, Pipa G, Neuenschwander S, Wibral M, Singer W (2011) A new look at gamma? High- $(>60 \mathrm{~Hz}) \gamma$-band activity in cortical networks: Function, mechanisms and impairment. Prog Biophys Mol Biol 105: $14-28$.

Vidal JR, Chaumon M, O’Regan JK, Tallon-Baudry C (2006) Visual grouping and the focusing of attention induce gamma-band oscillations at different frequencies in human magnetoencephalogram signals. J Cogn Neurosci 18:1850-1862.

Watts J, Thomson AM (2005) Excitatory and inhibitory connections show selectivity in the neocortex. J Physiol 562:89-97.

Whittington MA, Traub RD (2003) Interneuron diversity series: inhibitory interneurons and network oscillations in vitro. Trends Neurosci 26: $676-682$.

Whittington MA, Cunningham MO, LeBeau FE, Racca C, Traub RD (2011) Multiple origins of the cortical gamma rhythm. Dev Neurobiol 71: 92-106.

Wyart V, Tallon-Baudry C (2008) Neural dissociation between visual awareness and spatial attention. J Neurosci 28:2667-2679. 